\title{
Combinatorial prevention of carcinogenic risk in a model for familial colon cancer
}

\author{
NITIN TELANG ${ }^{1}$ and MEENA KATDARE ${ }^{2}$ \\ ${ }^{1}$ Carcinogenesis and Chemoprevention Research Laboratory, Strang Cancer Prevention Center and \\ ${ }^{2}$ Department of Surgery, Weill Medical College of Cornell University, New York, NY, USA
}

Received November 17, 2006; Accepted December 29, 2006

\begin{abstract}
Germ line mutations in the tumor suppressor adenomatous polyposis coli (APC) gene, predispose for the clinical familial adenomatous polyposis (FAP) syndrome, a high risk precursor for early onset colon cancer. Similar mutations in the murine homolog of the APC gene, however, produce adenomas predominantly in the small intestine, rather than in the colon. The objectives of the present study were: i) to develop a preclinical cell culture model for human FAP syndrome and ii) to validate this model as a rapid mechanism-based approach for evaluation of the preventive efficacy of combinations of synthetic pharmacological agents or naturally-occurring phytochemicals, for the risk of colon carcinogenesis. The clonally selected $850^{\mathrm{Min}} \mathrm{COL}-\mathrm{Cl}_{1}$ cell line derived from histologically normal colon of $\mathrm{Apc}^{\mathrm{Min}} /+$ mouse exhibited aberrant proliferation $(64.7 \%$ decrease in population doubling time, $820 \%$ increase in saturation density, and $81.4 \%$ decrease in spontaneous apoptosis), relative to that observed in the colon epithelial cell line C57 COL established from Apc [+/+] C57BL/6J mouse. In addition, unlike the Apc [+/+] C57 COL cells, the Apc mutant cells exhibited enhanced risk for spontaneous carcinogenic transformation as evidenced by $100 \%$ increase in anchorage-independent colony formation (C57 COL: 0/12; 850 ${ }^{\mathrm{Min}}$ COL-Cl 1 : 12/12, mean colony number

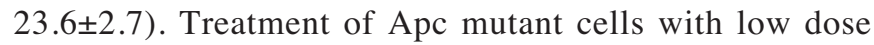
combination of select mechanistically distinct synthetic chemopreventive agents such as celecoxib (CLX) + difluoro methylornithine (DFMO), or naturally-occurring epigallocatechin gallate $(\mathrm{EGCG})+$ curcumin $(\mathrm{CUR})$ produced $160-400 \%$ and $220-430 \%$ decrease in the viable cell number
\end{abstract}

Correspondence to: Dr Nitin T. Telang, Strang Cancer Research Laboratory, The Rockefeller University, 1230 York Avenue, Box-231, New York, NY 10021, USA

E-mail: telangn@mail.rockefeller.edu or entitytoo@cs.com

Dr Meena Katdare, Department of Surgery, Weill Medical College of Cornell University, 1300 York Avenue, Box-287, New York, NY 10021, USA

E-mail: msk2004@med.cornell.edu

Key words: adenomatous polyposis coli mutation, carcinogenic risk, combinatorial prevention respectively, relative to these agents used independently. Furthermore, relative to independent agents, CLX+DFMO and EGCG+CUR combinations produced 31.5-82.1\% and $45.9-105.4 \%$ greater reduction in the number of anchorageindependent colonies. Thus, aberrant proliferation and increased risk for carcinogenesis in the Apc mutant cells, and their susceptibility to low dose combinations of mechanistically distinct chemopreventive agents validate a rapid approach to prioritize efficacious combinations for long-term animal studies and future clinical trials on prevention of colon cancer.

\section{Introduction}

Colon cancer is one of the major causes of morbidity and mortality in the US population, exhibiting a $21 \%$ cancer incidence (new cancer cases) and a $15 \%$ mortality (cancerrelated deaths) in 2006 (1). Stringently optimized specific and sensitive molecular/genetic biomarker assays continue to facilitate early diagnosis and better identification of cancer risk (2-4). However, patient response to traditional chemotherapy remains essentially unaltered, and is associated with adverse side-effects affecting compliance (4). Overall, these aspects emphasize a need for development of reliable models wherein new preventive/therapeutic modalities can be rapidly tested for safety, specificity and efficacy, and for their rational prioritization for subsequent animal experiments and future clinical trials.

In the multi-step process of familial colon carcinogenesis, germ line mutations in the tumor suppressor adenomatous polyposis coli (APC) gene represent the early occurring primary genetic defect. At the clinical level, this early occurring genetic defect characterizes the familial adenomatous polyposis (FAP) syndrome, a precursor for early onset familial colon cancer. It is noteworthy that somatic mutations in APC, together with those in ras, p53, ß-catenin or TGF- $\beta$ receptor genes are also detectable in familial, hereditary and sporadic colon cancer $(5,6)$.

The $\mathrm{Apc}^{\mathrm{Min}} /+$ mutant mouse model represents one of the most widely accepted preclinical animal models for colon cancer. This genetic model however, exhibits spontaneous carcinogenesis, predominantly in the small intestine, rather than in the colon, while the FAP syndrome predisposes for the early onset colon cancer (5-8). Recent evidence, however, has demonstrated that morphologically normal colonic tissue from the $\mathrm{Apc}^{\mathrm{Min} /+}$ mutant mouse exhibits up-regulated 
expression of genes associated with Apc/ß-catenin, NFkB and cell cycle regulatory pathways preceding the appearance of preneoplastic or neoplastic lesions $(9,10)$, suggesting a correlation of perturbed mechanistic biomarkers with an increased risk for carcinogenesis.

The $\mathrm{Apc}^{\mathrm{Min}} /+$ model has also been extensively utilized to evaluate preclinical efficacy of several mechanistically distinct synthetic pharmacological agents either independently or in combination (9). Low dose combinations of specific enzyme inhibitors, growth factor receptor antagonists, or pleiotropic naturally occurring phytochemicals exhibit enhanced preventive efficacy relative to that observed with these agents used independently $(2,3,9)$. Combinatorial intervention by the use of low dose combinations of synthetic pharmacological agents and/or naturally occurring phytochemicals may lead to reduced toxicity in favor of enhanced efficacy.

Reliable cell culture models expressing clinically relevant genetic defect at the appropriate target organ site and exhibiting quantifiable biomarkers for risk of spontaneous carcinogenesis, represent a novel paradigm as an alternative approach to facilitate rapid mechanism-based prioritization of efficacious chemopreventive agents (11-16). These compounds can be further tested through subsequent animal experiments and future clinical trials for prevention of colon cancer.

Previously optimized methodology to establish long-term subculturable colon epithelial cell lines from Apc $[+/+]$ and Apc $1638 \mathrm{~N}$ [+/-] mice $(11,12)$, has been utilized in the present study to demonstrate that the colon epithelial cell line derived from the $\mathrm{Apc}^{\mathrm{Min}} /+$ mouse is aberrantly proliferative and is at a higher risk for spontaneous carcinogenic transformation. Furthermore, the Apc mutant cells are susceptible to growth inhibition by combinations of mechanistically distinct synthetic pharmacological agents or naturally occurring phytochemicals. Thus, the data from this study validate a new preclinical cell culture model for early onset familial colon cancer as a mechanistic screen for the efficacy of combination of mechanistically distinct chemopreventive agents.

\section{Materials and methods}

Cell lines. The wild-type Apc [+/+] C57 COL cell line (source: descending colon of C57BL/6J mouse) and the mutant Apc $850^{\mathrm{Min}} \mathrm{COL}-\mathrm{Cl}_{1}$ cell line (source: descending colon of $\mathrm{Apc}^{\mathrm{Min}} /$ + mouse) were cultured in DME/F12 medium supplemented with heat inactivated $10 \%$ fetal calf serum, $0.24 \mathrm{IU} / \mathrm{ml}(10 \mu \mathrm{g} /$ $\mathrm{ml})$ insulin and $1 \mu \mathrm{M}$ dexamethasone. This culture medium also contained the antibiotic mixture $(100 \mathrm{IU} / 100 \mu \mathrm{g} / \mathrm{ml}$ penicillin/streptomycin $+50 \mu \mathrm{g} / \mathrm{ml}$ fungizone $+50 \mu \mathrm{g} / \mathrm{ml}$ gentamycin). Routinely, the stock cultures were maintained at $37^{\circ} \mathrm{C}$ in a humidified atmosphere of $95 \%$ air: $5 \% \mathrm{CO}_{2}$, fed with fresh medium every $48 \mathrm{~h}$, and were subcultured at 1:10 split at $70-80 \%$ confluency $(11,12)$. The Apc mutant $850^{\mathrm{Min}}$ COL- $\mathrm{Cl}_{1}$ cell line was clonally selected from a single anchorage-independent colony formed in $0.33 \%$ agar. This colony was dissociated and expanded as adherent culture in the DME/F12 medium similar to that used for the C57 COL cells.

Population doubling time and saturation density. The population doubling time was calculated from the viable cell
Table I. Aberrant proliferation in Apc mutant colon epithelial cell line.

\begin{tabular}{|c|c|c|}
\hline \multirow[b]{2}{*}{ Biomarker } & \multicolumn{2}{|c|}{ Cell line } \\
\hline & C57 COL & $850^{\text {Min }} \mathrm{COL}-\mathrm{Cl}_{1}$ \\
\hline Population doubling time $(\mathrm{h})^{\mathrm{a}}$ & 34 & 12 \\
\hline Viable cell number $\left(\mathrm{x} 10^{5}\right)^{\mathrm{b}}$ & $7.4 \pm 0.8$ & $67.9 \pm 4.6$ \\
\hline \multicolumn{3}{|l|}{ Anchorage-independent colonies ${ }^{\mathrm{c}}$} \\
\hline Incidence & $0 / 12$ & $12 / 12$ \\
\hline Frequency & - & $23.6 \pm 2.7$ \\
\hline
\end{tabular}

counts obtained at $24,48,72,96$ and $120 \mathrm{~h}$ post-seeding of $1.0 \times 10^{5}$ cells. These time points represent the duration of the exponential growth phase of the cell lines and are used to determine the population doubling time. The saturation density was determined from the total viable cell counts at the end of day 5 post-seeding of $1.0 \times 10^{5}$ cells.

Cell cycle progression. The cell cycle analysis was performed by determining flow cytometry-based percent distribution of propidium iodide-stained cells in the $\mathrm{G}_{0} / \mathrm{G}_{1}, \mathrm{~S}, \mathrm{G}_{2} / \mathrm{M}$ and sub $\mathrm{G}_{0}$ phases of the cell cycle. Briefly, trypsinized cell suspensions, after appropriate fixation and processing, were scanned on the Epic-752 flow cytometer equipped with a $488 \mathrm{nM}$ excitation and a $630 \mathrm{nM}$ long pass filter. The data from the cell cycle phase distribution were analyzed using the multi-cycle software $(11,13)$. The data obtained from at least $10^{4}$ fluorescent events were also expressed as $\mathrm{G}_{0} / \mathrm{G}_{1}: \mathrm{S}+\mathrm{G}_{2} / \mathrm{M}$ and $S+G_{2} / M: s u b G_{0}$ ratios to correlate the status of cell proliferation and cellular apoptosis.

Anchorage-independent colony formation (AICF). For this assay, cells suspended in $0.33 \%$ agar at an initial density of 100 cells/well were overlaid on a basement layer of $0.6 \%$ agar in six-well cluster plates. The cultures were maintained at $37^{\circ} \mathrm{C}$, and number of anchorage-independent colonies was determined at day 14 post-seeding.

Chemopreventive agents. Selective COX-2 inhibitor celecoxib (CLX), selective ornithine decarboxylase inhibitor difluoro methylornithine (DFMO), and the naturally occurring phytochemicals epigallocatechin gallate (EGCG) and curcumin (CUR) were selected as test compounds based on their documented efficacy in the $\mathrm{Apc}^{\mathrm{Min}} /+$ mouse model $(9,19,20,22-25,28)$, and their inclusion in several clinical trials $(26,27,29,30)$. The test compounds, obtained from Sigma Chemical Co., St. Louis, MO, were dissolved in 100\% ethanol (EtOH) to prepare a $100 \mathrm{mM}$ stock solution. These stock solutions were serially diluted in the culture medium to obtain $5 \log$ concentrations of $0.01,0.1,1,10$ and $100 \mu \mathrm{M}$ for the dose response experiments. 
Table II. Aberrant cell cycle progression in Apc mutant colon epithelial cell line.

\begin{tabular}{lccc}
\hline & \multicolumn{3}{c}{ Cell cycle analysis $^{\mathrm{a}}$} \\
\cline { 2 - 4 } Cell line & $\mathrm{G}_{0} / \mathrm{G}_{1}$ & $\mathrm{~S}+\mathrm{G}_{2} / \mathrm{M}$ & $\mathrm{Sub} \mathrm{G}_{0}$ \\
& $(\mathrm{Q})$ & $(\mathrm{P})$ & $(\mathrm{A})$ \\
\hline C57 COL & $75.4 \pm 1.6^{\mathrm{b}}$ & $24.8 \pm 3.3^{\mathrm{d}}$ & $4.3 \pm 1.1^{\mathrm{f}}$ \\
$850^{\text {Min }}$ COL-Cl & $21.8 \pm 0.5^{\mathrm{c}}$ & $78.2 \pm 2.0^{\mathrm{e}}$ & $0.8 \pm 0.5^{\mathrm{g}}$ \\
\hline
\end{tabular}

${ }^{a}$ Flow cytometry data generated from $10^{4}$ fluorescent events. Mean $\pm \mathrm{SD}, \mathrm{n}=6$ per cell line. Q, quiescent; $\mathrm{P}$, proliferative; A, apoptotic; $\mathrm{b}-\mathrm{c}, \mathrm{d}-\mathrm{e}, \mathrm{f}-\mathrm{g} \mathrm{p}=0.001$.

Dose response of chemopreventive agents. To evaluate the growth inhibitory effects of CLX, DFMO, EGCG and CUR, the Apc mutant cells were seeded at the initial seeding density of $1.0 \times 10^{5}$ cells in T-25 flasks. After an attachment period of $24 \mathrm{~h}$, the cultures were continuously treated with $5 \log \mu \mathrm{M}$ concentrations of individual agents for the duration of the exponential growth phase. The cultures were fed with fresh medium containing the test compounds every $48 \mathrm{~h}$ and cell counts of viable cells were obtained at day 5 post-seeding. Control cultures in parallel were treated with $0.1 \% \mathrm{EtOH}$ (solvent controls), comparable to that present in $100 \mu \mathrm{M}$ concentration of the test compounds. The primary cell count data were converted to inhibitory concentration (IC) range and expressed as $\mathrm{IC}_{50}$ values.

\section{Results}

Aberrant proliferation and risk for carcinogenic transformation. The status of aberrant proliferation and the risk for carcinogenic transformation was evaluated in the Apc $[+/+]$ $\mathrm{C} 57 \mathrm{COL}$ and the Apc mutant $850^{\mathrm{Min}} \mathrm{COL}-\mathrm{Cl}_{1}$ cells by determining population doubling time (PDT), viable cell number representing saturation density, and anchorage-independent colony formation (AICF). Relative to C57 COL cells, the Apc mutant $850^{\mathrm{Min}} \mathrm{COL}-\mathrm{Cl}_{1}$ cells exhibited a $64.7 \%$ decrease in PDT and an $820 \%$ increase in the total viable cell number at day 5 post-seeding of $1.0 \times 10^{5}$ cells. Furthermore, the C57 COL cells lacked AICF (0/12), whereas, the Apc mutant cells exhibited a $100 \%$ incidence $(12 / 12)$, with a mean colony number of $23.6 \pm 2.7$ (Table I).

The aberrant proliferation exhibited a correlation with altered cell cycle progression. Thus, relative to the C57 COL cells, the Apc mutant cells exhibited a $71.1 \%$ decrease in $\mathrm{G}_{0} / \mathrm{G}_{1}$ population, a $217 \%$ increase in $\mathrm{S}+\mathrm{G}_{2} / \mathrm{M}$ population and an $81.4 \%$ decrease in sub $\mathrm{G}_{0}$ apoptotic population (Table II). These alterations in the cell cycle progression resulted in a 9.3-fold decrease in $Q\left(\mathrm{G}_{0} / \mathrm{G}_{1}\right): \mathrm{P}\left(\mathrm{S}+\mathrm{G}_{2} / \mathrm{M}\right)$ ratio, and a 15.9-fold increase in $P\left(S+G_{2} / M\right): A\left(s_{b} G_{0}\right)$ ratio. Thus, these data taken together suggest that aberrantly proliferative Apc mutant cells also have down-regulated cellular apoptosis.
Table III. In vivo pharmacokinetics and in vitro dose response of chemopreventive agents on Apc mutant colon epithelial cell line.

\begin{tabular}{lcc}
\hline Agent & $\begin{array}{c}\mathrm{Apc}^{\mathrm{Min}} /+ \\
\text { plasma levels }(\mu \mathrm{M})\end{array}$ & $\begin{array}{c}\text { Inhibitory concentration }(\mu \mathrm{M})^{\mathrm{a}} \\
\mathrm{IC}_{50} 850^{\mathrm{Min}} \mathrm{COL}-\mathrm{Cl}_{1}\end{array}$ \\
\hline $\mathrm{CLX}^{\mathrm{b}}$ & $2.0-6.0$ & $8.1 \pm 0.4$ \\
$\mathrm{DFMO}^{\mathrm{c}}$ & $86-225$ & $35.1 \pm 0.4$ \\
$\mathrm{EGCG}^{\mathrm{d}}$ & $0.3-2.0$ & $0.7 \pm 0.1$ \\
$\mathrm{CUR}^{\mathrm{e}}$ & $0.8-2.5$ & $29.6 \pm 0.4$ \\
\hline
\end{tabular}

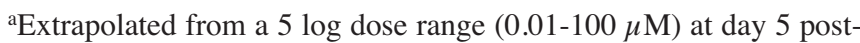
seeding of $1.0 \times 10^{5}$ cells. ${ }^{\mathrm{b}}(23),{ }^{\mathrm{c}}(31),{ }^{\mathrm{d}}(36),{ }^{\mathrm{e}}(28)$.

Susceptibility to chemopreventive agents. The susceptibility of Apc mutant cells to growth inhibitory effects of CLX, DFMO, EGCG and CUR was evaluated by an initial doseresponse experiment involving $5 \log$ concentrations $(0.01$, $0.1,1,10$ and $100 \mu \mathrm{M})$ of each compound in a 5-day growth assay. The growth modulation in the solvent controls was minimal and comparable with that observed in the untreated master controls. These primary data were converted to $\mathrm{IC}_{50}$ values to rank the efficacy of the chemopreventive agents for growth inhibition, and to compare the $\mathrm{IC}_{50}$ values with the reported in vivo plasma levels. In comparison with the plasma levels of CLX, DFMO and EGCG, observed in vitro, $\mathrm{IC}_{50}$ values of these three agents were essentially within the pharmacologically achievable range. The rank order for efficacy followed the EGCG $>$ CLX $>$ CUR $>$ DFMO sequence (Table III).

Combinatorial efficacy of chemopreventive agents. The efficacy of low dose combinations of mechanistically distinct compounds was evaluated by using each compound independently and in combination at less than their individual $\mathrm{IC}_{20}$ concentrations. Viable cell number at day 5 post-seeding and AICF at day 14 post-seeding represented the quantitative endpoints. The combination of pharmacological compounds CLX+DFMO exhibited at least a $240 \%$ greater decrease in viable cell number and a $52.6 \%$ greater decrease in AICF relative to that produced by these compounds used independently. Similarly, the combination of natural phytochemicals EGCG+CUR produced at least a $300 \%$ and a $70.6 \%$ greater inhibition in two end-points, relative to that produced by these compounds used independently (Table IV).

\section{Discussion}

The Apc $\mathrm{Ain}^{\mathrm{M}}+$ mouse, because of a germ line mutation in codon 850 of the Apc gene, exhibits a high incidence of spontaneous adenomas in the small intestine and represents a genetic preclinical model for clinical colon cancer (5-9). However, unlike that in clinical FAP patients, the colonic segments of the Min mouse exhibit low incidence of adenoma and carcinoma $(5,7,8)$. It is noteworthy that colon carcinogenesis is experimentally induced in the Min mouse model. Thus, 
Table IV. Efficacy of chemopreventive agents for growth inhibition of Apc mutant colon epithelial cells.

\begin{tabular}{lccccc}
\hline Agent & Concentration & ${\text { Viable cells }\left(\times 10^{5}\right)}^{\mathrm{a}}$ & Inhibition $(\%)$ & Number of colonies & Inhibition $(\%)^{\mathrm{b}}$ \\
\hline EtOH & $0.01 \%$ & $65.3 \pm 4.6^{\mathrm{c}}$ & - & $27.0 \pm 3.2^{\mathrm{f}}$ & - \\
CLX & $1 \mu \mathrm{M}$ & $60.8 \pm 4.3$ & 6.9 & $14.8 \pm 3.2$ & 45.2 \\
DFMO & $10 \mu \mathrm{M}$ & $56.6 \pm 2.8$ & 13.3 & $10.1 \pm 1.2$ & 62.6 \\
CLX+DFMO & $1+10 \mu \mathrm{M}$ & $43.1 \pm 3.0^{\mathrm{d}}$ & 33.9 & $4.8 \pm 0.6^{\mathrm{g}}$ & 82.2 \\
& & & & & \\
EGCG & $0.1 \mu \mathrm{M}$ & $58.7 \pm 4.1$ & 10.1 & $16.0 \pm 1.9$ & 40.7 \\
CUR & $10 \mu \mathrm{M}$ & $54.5 \pm 3.8$ & 16.5 & $4.4 \pm 0.5^{\mathrm{g}}$ & 57.4 \\
EGCG+CUR & $0.1+10 \mu \mathrm{M}$ & $30.5 \pm 2.1^{\mathrm{e}}$ & 53.3 & 83.7 \\
\hline
\end{tabular}

a Determined at day 5 post-seeding of $1.0 \times 10^{5}$ cells. Mean \pm SD, $n=6$ per treatment group. ${ }^{b}$ Determined at day 14 post-seeding of 100 cells per well. Mean $\pm \mathrm{SD}, \mathrm{n}=12$ per treatment group. ${ }^{\mathrm{c}-\mathrm{d}, \mathrm{c}-\mathrm{e}} \mathrm{p}=0.01,{ }^{\mathrm{f}-\mathrm{g}} \mathrm{p}=0.005$.

administration of the chemical carcinogen azoxymethane (18), and of the PPAR- $\gamma$ agonist troglitazone $(19,20)$ results in a high incidence of colonic adenoma and adenocarcinoma. Additionally, genetic modulation such as that in Apc $\mathrm{An}^{\mathrm{Min}} \mathrm{BubR} 1$ double mutants (21), Smad-3 mutants (45) and Apc ${ }^{\mathrm{Min} /+} /$ Smad-3 $3^{-/}$double mutants (46) results in accelerated carcinogenesis in the colon. These observations taken together provide evidence for a stronger clinical relevance for the present model of FAP syndrome. Comparative genomic (10) and proteomic (40) data on non-involved colonic mucosal epithelium and adenomatous polyps have demonstrated that the target tissue at risk exhibits distinct gene/protein expression profiles well before the advent of pathogenic changes associated with tumorigenesis, and that these early-occurring molecular alterations are similar to those in adenomas. These data suggest that distinct expression profiles may identify better indicators of carcinogenic risk.

Availability of reliable cell culture models expressing clinically relevant genetic defect (APC mutation) at the appropriate target organ site (colon) with quantifiable biomarkers of risk for carcinogenic transformation $(11,12)$, may eliminate the limitations of the in vivo models, and therefore, represent a valuable complementary approach to long-term animal studies.

The present study demonstrates that the $850^{\mathrm{Min}} \mathrm{COL}-\mathrm{Cl}_{1}$ cells originated from morphologically normal descending colon of the $\mathrm{Apc}^{\mathrm{Min}} /+$ mouse are aberrantly proliferative as evidenced by shorter PDT, higher saturation density, higher number of cells in the $\mathrm{S}+\mathrm{G}_{2} / \mathrm{M}$ phase of the cell cycle, and decreased cellular apoptosis. These Apc mutant cells also exhibit higher risk for spontaneous carcinogenic transformation as evidenced by high incidence and frequency of AICF. Consistent with these observations, previous studies have shown that mammary epithelial cells independently transfected with Ras (15), myc (16) or HER-2/neu (17) oncogenes also exhibit aberrant proliferation that is associated with accelerated cell cycle progression and down-regulated cellular apoptosis. Furthermore, these oncogene expressing cells exhibit high incidence of AICF in vitro preceding carcinogenesis upon in vivo transplantation. Thus, AICF represents a sensitive and specific in vitro surrogate end-point biomarker for in vivo carcinogenic transformation. Noninvolved colonic tissue from $\mathrm{Apc}^{\mathrm{Min}} /+$ mouse has been demonstrated to exhibit up-regulation of genes associated with the Apc/B-catenin, NFKB pathways and with cell cycle progression (10). These observations together with the phenomenological data from the present study provide a strong rationale to examine whether aberrantly proliferative preneoplastic $850^{\mathrm{Min}} \mathrm{COL}-\mathrm{Cl}_{1}$ also exhibit up-regulated expression of molecular targets that are associated with the risk for carcinogenesis.

The Apc $\mathrm{Ain} /+$ mouse model has been used for preclinical efficacy of several pharmacological as well as naturally occurring chemopreventive compounds as single agents that include synthetic NSAIDs (22), selective COX-2 inhibitors (23-25), selective inhibitors of polyamine biosynthetic pathway $(26,44)$, selective antagonists of growth factor receptor function (27), and several naturally-occurring phytochemicals $(9,28)$. Long-term administration of these synthetic pharmacological agents at high doses is associated with systemic toxicity (2-4,29,30). In addition, recent preclinical evidence has shown that long-term administration of the selective COX-2 inhibitor CLX is associated with recurrence of intestinal adenomas in the $\mathrm{Apc}^{\mathrm{Min}}$ mouse model (38). Enhanced efficacy of low dose combinations of several mechanistically distinct synthetic pharmacological agents such as piroxicam + difluro methylornithine (31), sulindac + EGFR antagonist (32), and atorvastatin + CLX (39) has been demonstrated in vivo in the $\mathrm{Apc}^{\mathrm{Min}}$ mouse model. In addition to the combinations of synthetic pharmacological agents, several mechanistically distinct natural phytochemicals have been reported to enhance the efficacy of conventional chemotherapy, leading to a reduction in toxicity $(33,41-44)$. Consistent with these observations, low dose combinations of CLX+DFMO and EGCG+CUR have demonstrated higher efficacy in the present preclinical cell culture model for FAP syndrome, emphasizing the validity of this model.

The ability of combination of mechanistically distinct CLX+DFMO or EGCG+CUR to affect the growth of aberrantly proliferative Apc mutant $850^{\mathrm{Min}} \mathrm{COL}-\mathrm{Cl}_{1}$ cells now facilitates rational studies designed to examine the modulation of relevant molecular targets such as cell cycle 
regulatory proteins and Apc/B-catenin mitogenic signal transduction cascade. In addition, the present model facilitates future studies focused on specific targets that are known to be responsible for preventive efficacy such as COX-2 for CLX (23-25), ornithine decarboxylase for DFMO (26,31), EGF receptor signaling and generation of reactive oxygen species for EGCG (34-36), and NFKB signaling for CUR (37).

In conclusion, the present cell culture model exhibiting quantifiable risk for carcinogenic transformation provides a rapid mechanism-based approach for rational prioritization of effective combinatorial interventions in long-term animal studies and future clinical trials on prevention of colon cancer.

\section{Acknowledgements}

We thank Milan Zvanovec and Tonye Briggs for their excellent technical assistance. This research has been supported in part by NIH grants CA 29502-S1 and CN 75029-63 (N.T.) and CA 29502-20 and CA 122394 (M.K.), and funds from The Irving Weinstein Foundation (N.T. and M.K.).

\section{References}

1. Jemal A, Murray T, Ward E, et al: Cancer Statistics-2006. Cancer J Clin 56: 106-130, 2006.

2. Abbruzzese JL and Lippman SM: The convergence of prevention and therapy in early phase clinical drug development. Cancer Cell 6: 321-326, 2004.

3. Hong WK and Sporn MB: Recent advances in chemoprevention of cancer. Science 278: 1073-1077, 1997

4. Kelloff GJ, Lippman SM, Dannenberg AJ, et al: Progress in chemoprevention drug development: the promise of molecular biomarkers for prevention of intraepithelial neoplasia and cancer, a plan to move forward. Clin Cancer Res 12: 3661-3697, 2006.

5. Fodde R, Smits R and Cleavers H: APC signal transduction and genetic instability in colorectal cancer. Nat Rev Cancer 1: 5-67, 2001.

6. Fearon ER and Vogelstein B: A genetic model for colorectal tumorigenesis. Cell 61: 759-767, 1990.

7. Moser AR, Pitot HC and Dove WF: A dominant mutation that predisposes to multiple intestinal neoplasia in the mouse. Science 247: 322-324, 1990.

8. Su L-K, Kinzler KW, Vogelstein B, et al: Multiple intestinal neoplasia caused by a mutation in the murine homolog of the APC gene. Science 256: 688-670, 1992.

9. Corbet DE and Pierre F: Point: From animal models to prevention of colon cancer. Systemic review of chemoprevention in Min mice and choice of the model system. Cancer Epid Biomark Prev 12: 391-400, 2003.

10. Chen L-G, Hao C-Y, Chiu YSY, et al: Alteration of gene expression in normal appearing colon mucosa of $\mathrm{APC}^{\mathrm{Min}}$ mice and human cancer patients. Cancer Res 64: 3694-3700, 2004.

11. Katdare M, Kopelovich L and Telang N: Efficacy of chemopreventive agents for growth inhibition of APC [+/-] 1638N COL colonic epithelial cells. Int J Mol Med 10: 427-432, 2002.

12. Telang NT, Li G and Katdare M: Prevention of early onset familial/hereditary colon cancer: New models and mechanistic biomarkers (Review). Int J Oncol 28: 1523-1529, 2006.

13. Katdare M, Osborne M and Telang N: Soy isoflavone genistein modulates cell cycle progression and induces apoptosis in HER-2/ neu oncogene expressing human breast epithelial cells. Int J Oncol 21: 809-815, 2002.

14. Katdare M, Osborne MP and Telang NT: Novel cell culture models for prevention of human breast cancer (Review). Int $\mathrm{J}$ Oncol 22: 509-515, 2003.

15. Telang NT, Narayanan R, Bradlow HL, et al: Co-ordinated expression of intermediate biomarkers for tumorigenic transformation of Ras-transfected mouse mammary epithelial cells. Breast Cancer Res Treat 18: 155-163, 1991.
16. Telang NT, Osborne MP, Sweterlitsch LA, et al: Neoplastic transformation of mouse mammary epithelial cells by deregulated myc expression. Cell Regul 1: 863-872, 1990.

17. Zhai YF, Beittenmiller H, Wang B, et al: Increased expression of specific tyrosine phosphatases in human breast epithelial cells neoplastically transformed by the neu oncogene. Cancer Res 53: 2272-2278, 1993.

18. Paulson JE, Steffensen J-L, Loberg EM, et al: Quantitative and qualitative relationship between displastic aberrant crypt foci and tumorigenesis in the Min/+ mouse colon. Cancer Res 61: 5010-5015, 2001.

19. Saez E, Tontonoz P, Nelson MC, et al: Activators of the nuclear receptor PPAR- $\gamma$ enhance colon polyp formation. Nat Med 4: 1058-1061, 1998.

20. Lefebvre AM, Chen IH, Desrelmaux P, et al: Activation of peroxisome proliferator activated receptor promotes the development of colon tumors in C57BL/6J-APC $\mathrm{Min} /+$ mice. Nat Med 4: 1053-1057, 1998.

21. Rao CV, Yang YM, Swamy MV, et al: Colonic tumorigenesis in BubR1 [+/-]/Apc ${ }^{\mathrm{Min} /+}$ compound mutant mice is linked to premature separation of sister chromatid and enhanced genomic instability. Proc Natl Acad Sci USA 102: 4365-4370, 2005.

22. Beazer-Barclay Y, Levy DB, Moser AR, et al: Sulindac suppresses tumorigenesis in the Min mouse. Carcinogenesis 17: 1757-1760, 1996.

23. Jacoby RF, Siebert K, Cole CE, et al: The cyclo-oxygenase inhibitor Celecoxib is a potent preventive and therapeutic agent in the Min mouse model of adenomatous polyposis. Cancer Res 60: 5040-5044, 2000 .

24. Oshima M, Murai (Hata) N, Kargman S, et al: Chemoprevention of intestinal polyposis in the $\mathrm{APC}^{716}$ mouse by Rofecoxib, a specific cyclo-oxygenase-2 inhibitor. Cancer Res 61: 1733-1740, 2001.

25. Sasai S, Masaki M and Wakitami K: Suppression of polypogenesis in a new mouse strain with a truncated $\mathrm{APC}^{474}$ by a novel COX-2 inhibitor JTE-522. Carcinogenesis 21: 953-958, 2000.

26. Gerner EW and Meyskens FL: Polyamines and cancer: old molecules, new understanding. Nat Rev Cancer 4: 785-792, 2004.

27. Woodburn JR: The epidermal growth factor receptor and its inhibition in cancer therapy. Pharmacol Ther 82: 241-250, 1999.

28. Perkins S, Verschoyle RD, Hill F, et al: Chemopreventive efficacy and pharmacokinetics of Curcumin in the Min/+ mouse, a model for familial adenomatous polyposis. Cancer Epid Biomark Prev 11: 535-540, 2002.

29. Solomon SD, McMurray JJV, Pfeffer M, et al: Cardiovascular risk associated with Celecoxib in a clinical trial for colorectal adenoma prevention. N Engl J Med 352: 1071-1080, 2005.

30. Bresalier RS, Sandler RS, Quan H, et al: Cardiovascular events associated with Rofecoxib in a colorectal adenoma chemoprevention trial. N Engl J Med 352: 1092-1102, 2005.

31. Jacoby RF, Cole CE, Tutsch F, et al: Chemopreventive efficacy of combined piroxicam and difluoro methylornithine treatment on APC mutant Min mouse adenoma and selective toxicity against APC mutant embryos. Cancer Res 60: 1864-1870, 2000 .

32. Torrance CJ, Jackson PE, Montgomery E, et al: Combinatorial chemoprevention of intestinal neoplasia. Nat Med 6: 1024-1028, 2000.

33. Swamy MV, Cooma I, Jagan MR, et al: Modulation of COX-2 activity by combined action of celecoxib and docohexaenoic acid. Mol Cancer Ther 3: 215-223, 2004.

34. Ju J, Hong J, Zhou J-N, et al: Inhibition of intestinal tumorigenesis in APC Min/+ mice by (-)-Epigallocatechin-3-Gallate, the major catechin in green tea. Cancer Res 65: 10623-10631, 2005.

35. Khan N, Afaq F, Saleem M, et al: Targeting multiple signaling pathways by green tea polyphenol (-)-Epigallocatechin-3gallate. Cancer Res 66: 2500-2505, 2006.

36. Yang CS, Maliakal P and Meng X: Inhibition of carcinogenesis by tea. Annu Rev Pharmacol Toxicol 42: 25-54, 2002.

37. Bharati AC and Aggarwal BB: Nuclear factor $\kappa B$ and cancer: its role in prevention and therapy. Biochem Pharmacol 64: 883-888, 2002.

38. Carothers AM, Moran AE, Cho NL, et al: Changes in antitumor response in $\mathrm{C} 57 \mathrm{BL} / 6 \mathrm{~J}-\mathrm{Min} /+$ mice during long term administration of a selective cyclo-oxygenase inhibitor. Cancer Res 66: 6432-6438, 2006. 
39. Swamy MV, Patlolla JMR, Steele VE, et al: Chemoprevention of familial adenomatous polyposis by low doses of Atorvastatin and Celecoxib given individually and in combination to $\mathrm{APC}^{\mathrm{Min}}$ mice. Cancer Res 66: 7370-7377, 2006.

40. Polley ACJ, Mulholand F, Pin C, et al: Proteomic analysis reveals field wide changes in protein expression in the morphologically normal colon of patients with colorectal neoplasia. Cancer Res 66: 6553-6562, 2006.

41. Surh YJ: Cancer chemoprevention with dietary phytochemicals. Nat Rev Cancer 3: 768-780, 2003.

42. Levi-Ari S, Strier L, Kazanov D, et al: Celecoxib and curcumin synergistically inhibit the growth of colorectal cancer cells. Clin Cancer Res 11: 6738-6744, 2005.
43. Sarkar FH and Li Y: Using chemopreventive agents to enhance the efficacy of cancer chemotherapy. Cancer Res 66: 3347-3350, 2006.

44. Krishnan K, Ruffin MT and Brenner DE: Chemoprevention of colorectal cancer. Crit Rev Oncol 33: 199-219, 2000.

45. Zhu Y, Richardson JA, Parada LF, et al: Smad-3 mutant mice develop metastatic colorectal cancer. Cell 94: 703-714, 1998.

46. Sodir NM, Chen X, Park R, et al: Smad-3 deficiency promotes tumorigenesis in the distal colon of $\mathrm{Apc}^{\mathrm{Min} /+}$ mice. Cancer Res 66: 8430-8438, 2006. 